\title{
An Evaluation of Multisource Feedback (MSF) for Managerial Development in Large-Size Manufacturing Companies in Thailand
}

\author{
Phongstorn Ermongkonchai \\ Charles Sturt University \\ E-Mail: phongstorn@yahoo.com
}

\begin{abstract}
As performance appraisal method known as multisource feedback (MSF) or $360^{\circ}$ feedback was popular in Western organizations for decades, it is questionable if the practice will offer similar benefits at international level. In this article, the literature on multisource feedback and comparative culture is reviewed. Based upon practices suggested by recent literature, a research was conducted at the two large-size organizations in Thailand. This research found that managers can accept the multisource feedback for development purpose. Negative cultural implications can be avoided while maintaining the merits of multisource feedback for employee development.
\end{abstract}

Keywords: Human Resource Management, Performance Appraisal, Human Resource Development, culture, Thailand

\section{BACKGROUND}

In strategic human resource management, one of the essential tasks is to align employees with common vision and values to achieve company strategies and objectives (Williams, 1996; Mabey, Salaman, \& Storey, 1998; Kramar, 1998; Stone, 1998). In doing so, human resource management uses performance management processes to manage employee performance, such as staffing, training and reward (Williams, 1996; Marshall, 2000; Kramar, 1998).

Multisource feedback or $360^{\circ}$ feedback is an extension of traditional performance appraisal by collecting information from employee, subordinates, peers, supervisors and 
customers (Tornow, 1993; London \& Smither, 1995; Edwards \& Ewen, 1996; Atwater et al., 1998; Wood et al., 2000). Multisource feedback is often used as developmental tool and recently, it has been introduced as evaluative tool to complement performance management system (Edwards \& Ewen, 1996; London, Smither, \& Adsit, 1997).

In the past decade, researches have indicated that the use of multisource feedback has grown in popularity in the United States with more than 90 percent of Fortune 500 companies use some forms of multisource feedback system (Edward \& Ewen, 1996; Nankervis, Compton, \& Baird, 2002). At company level, multisource feedback has proved to be useful in terms of aligning individual behaviour and performance with corporate values, such as reinforcing team behaviours (Edward \& Ewen, 1996), implementing strategic initiatives and implementation of Total Quality Management (Edward \& Ewen et al., 1996). At employee level, multisource feedback is well-accepted by fostering employee involvement (London \& Beatty, 1993), providing fair and accurate performance feedback and leads to self-development (Hazucha, Hezlett, \& Schneider, 1993).

Given the popularity of the system in the U.S. and Europe, scholars have raised concerns on the transferability of multisource feedback to other culture, especially in Eastern cultures (Entrekin \& Chung, 2001; Hofstede, 2001). Although Thai managers were modernized by Western management style education, the culture of Thai managers is strongly influenced in many respects by traditional Thai customs and Buddhism believes (Komin, 1991; Klausner, 1993). Thai cultures and Americans have been seen to differ in terms of cultural characteristics.

With respect to the transferability of management practices internationally, Laurent (1986) and Schneider (1988) contend that human resource management practices seem to be the most vulnerable to cultural relativity. In this context, Hofstede (2001) has cautioned that performance appraisal should be appropriately adjusted to culture with specific characteristics. Researches by Bernardin and Beatty (1984), and Bernardin et al. (1993) have indicated that attitudes towards the appraisal system and its sources may have a profound effect on the ultimate effectiveness of that system. Following these recommendations, the purpose of the present study is to examine the perceptions of Thai managers to multisource feedback for managerial development. 


\section{RESEARCH OBJECTIVES}

The purpose of this study is to understand the current practice of multisource feedback available. As there is limited prior research conducted on this issue in Thailand, the study aims to examine the perceptions of Thai managers on the usage of multisource feedback as self-developmental tool on the following:

- perceived usefulness to the employees;

- perceptions on fairness, accuracy, and credibility; and

- perceptions on multisource feedback as a development tool.

\section{Research Questions}

The key questions to be examined in this study of multisource feedback will include the investigation of the following:

Overall perceptions

- What is the perceived usefulness to the employees?

- Is the feedback fair, accurate and credible?

- Do the employees believe in the feedback?

- Which raters are more credible to employee, self or other-raters?

- What is the perception of the feedback from supervisor? Subordinates? Peers?

\section{Self-Development}

- What is the impact on self-development?

- Does the feedback motivate self-development?

\section{Significance of Research}

With the popularity of multisource feedback in the U.S., the practice on the use of multisource feedback system in Southeast Asia is not common. As the research on multisource feedback in Thailand is not available, this study attempts to conduct an actual usage of the system and investigate users' evaluation of multisource feedback for further development. This research aims to investigate the perceptions of multisource feedback in the large-size manufacturing and marketing firm in Thailand. The findings will be useful for improvement on the practice of multisource feedback in Thailand. 


\section{LITERATURE REVIEW}

\section{Prior Research on the Topic}

From a theoretical perspective, multisource feedback provides an increased in reliability (reduction in measurement error) and validity (greater coverage of the individual performance domain) vis-a-vis traditional supervisor-subordinate appraisal (Edwards \& Ewen, 1996; Brutus \& Derayeh, 2002). Multisource feedback is based on two major assumptions. Firstly, individuals will increase self-awareness from understanding different perceptions from their constituents. Consequently, they may develop a more accurate sense of goal accomplishment and self-competence. Secondly, individuals will be provided with feedback on strengths and weaknesses for skill development and performance improvement (Tornow, 1993; London \& Smither, 1995; Church \& Bracken, 1997; Brutus \& Derayeh, 2002).

\section{Usefulness of Multisource Feedback}

Drawing upon researches by London and Beatty (1993), Edwards and Ewen (1996), and Bracken et al. (2001), multisource feedback is beneficial at the organisation level in many ways. Firstly, companies use multisource feedback to introduce organizational culture change, to enhance two-way communication and to encourage positive attitude toward learning; for example, to foster working culture on participative leadership, empowerment, customer service, quality focus, re-engineering, competency-based rewards and team-based rewards (Edwards \& Ewen, 1996; Peiperl, 2001; Nankervis et al., 2002). Secondly, multisource feedback is used as a tool to help sustain focused behavioural change in majority of employees that leads to the organizational effectiveness. Thirdly, it is used to align employee performance expectations with corporate values. In this aspect, it can call attention to the important performance dimensions neglected by organization. Fourthly, companies use multisource feedback to increase employee competencies on changing needs at work, i.e. an increased span of control, more knowledgeable workers, practices of project management and teamwork. In the fifth way, multisource feedback is used to improve employee relations on different aspects, for instance, career development, fair reward decisions, accurate performance measures, valid performance measures, non-performance, diversity management, and legal protection. In the sixth way, it assists organization to increase legal defensibility in relations to employee appraisal (London \& Beatty, 1993; Edwards \& Ewen, 1996; 
Bracken et al., 2001).

At employee level, a survey report on the use of multisource feedback indicated that 92\% of users find the report useful for self-development (London et al., 1990). Antonioni (1996) and Edwards and Ewen (1996) have reported further benefits to serve individual needs. Firstly, multisource feedback is perceived by employees as being fair, accurate, credible and motivating (Harris \& Schaubroeck, 1988; London et al., 1990; London \& Beatty, 1993). Secondly, multisource feedback is applicable to all professions. Thirdly, it creates employee accountability and service to all stakeholders. Finally, multisource feedback is an effective system to encourage employees' participation (Antonioni, 1996; Edwards \& Ewen, 1996; Brutus \& Derayeh, 2002).

One of the most important pieces of research on the contributions of multisource feedback was conducted by Hazucha, Hezlett and Schneider (1993). They have found that participants' skills would increase after receiving multisource feedbacks which identify their strengths and weaknesses for development. In addition, an increase in selfawareness from multiple perspectives causes individuals to improve themselves from program implementation. In another study, London and Smither (1995) have found that multisource feedback improves individual goals, skill development, behaviour and performance through self-image re-evaluation moderated by schemas, task self-efficacy, and impression management.

Other academics and practitioners have reported the usefulness of multisource feedback in different aspects. Previous researchas reported that receivers of the reports found multisource feedback motivating individuals to address development needs. Mabey (2001) has found that multisource feedback provides significant benefits to be used with training and developing individuals. Nilsen and Campbell (1993) have indicated that it encourages employees' participation and improves overall appraisal satisfaction, and at the same time, provides self-assessment ratings as reliable measures of behaviors.

Studies have indicated that multisource feedback has improved reliability and validity of performance appraisal, such as reduction of halo, central tendency and leniency errors (London \& Beatty, 1993; Edwards \& Ewen, 1996; Arvey \& Murphy, 1998). More importantly, the use of average ratings by subordinates has shown to have acceptable predictive validity of future performances (McEvoy \& Beatty, 1989). In terms of reliability, Pollack D. and Pollack L (1996) have found that rating reliability of others and peers are found to be valid predictors of performances. 


\section{Weaknesses of Multisource Feedback}

In terms of weaknesses, multisource feedback is criticized in different respects. Moses, Hollenbeck and Sorcher (1993) have indicated weaknesses in five important points. Firstly, multisource feedback is criticized as being over-reliant on the generalized traits of individuals. Secondly, it relies on the limited or nonexistent frame-of-references for making judgments. Thirdly, multisource feedback is criticized as being based on incomplete description of past performance. Fourthly, there are doubts on observers' view to interpret ratings and behaviours. Lastly, multisource feedback is seen as being over-reliant on designer scoring system for administration (Moses et al., 1993).

Brutus and Derayehn (2002) have criticized that many organisations are implementing multisource feedback without a clear strategy. The lack of strategy causes doubts about the linkage of the system to other development systems; for example, participant selection, incorporation with formal performance appraisal practices, effort to follow up and other coaching support. Furthermore, there were reports that some system designs of ratings lack face validity, especially when used at varying organizational levels. For example, a rating item may be interpreted differently as employees at different levels vary in backgrounds and educational levels (Brutus \& Derayeh 2002). Frisch (2001) has pinpointed that multisource feedback method may dis-align supporting function employees away from their job objectives, e.g. information technology, research and development, logistics, loss prevention, electronic security and business development.

Peiperl (2001) has suggested that multisource feedback may not be suitable for high performance teams. As the feedback is aimed and provided with reward for individual performance improvement, the practice may harm existing close relationship among members and successful groups (Seifert, 2001). Maund (2001) has supported this finding by suggesting that multisource feedback for high performance team should not include subordinate ratings as reports may divert individuals' attentions from team focus.

Similar to traditional performance appraisal, multisource feedback is also criticized that it may be vulnerable to employee manipulation (Edwards \& Ewen, 1996; Mabey et al., 1998; Frisch, 2001; Brutus \& Derayeh, 2002), or appraisers may not give frank or honest feedbacks (London et al., 1990). In terms of effectiveness, the impact created by the feedback is temporary when there is a lack of action following feedback (Kaplan, 1993; London et al., 1997). In terms of accuracy, Dierdorff and Surface (2007) have found that peer ratings are attributable to systematic sources beyond the actual 
performance of the employee rated. The findings indicated that ratings results are influenced by rating situations in addition to employee performance. Furthermore, research by (Brett \& Atwater, 2001) have revealed that negative feedbacks from multisource feedback method may not be seen as accurate or useful in which case it may lead to anger and discouragements.

Brutus and Derayeh (2002) have further reported on resistance to multisource feedback on the time and effort required and lack of trust in the system. For example, as high as $67 \%$ of employees felt that feedback is not worth the effort of administering the required forms, especially when managers have larger span of control. In terms of trust on the system, there was a fear on being identified from peers or supervisors even though rater anonymity was guaranteed. Multisource feedback has also been criticized on not having sufficient empirical research to suggest system effectiveness (Smither et al. 1995). As a result, practitioners are using the feedback method on a trial-and-error basis (Greguras \& Robie, 1998).

In terms of international use, the popularity of multisource feedback is still concentrated on companies in the U.S. and Europe. There is a limited use of multisource feedback in Asia and Australia. This research aims to fill the gaps to conduct a study on the use of multisource feedback in Thailand.

\section{CROSS-CULTURAL ISSUES OF PERFORMANCE APPRAISAL AND MULTISOURCE FEEDBACK}

For performance appraisal system to be used at international level, Hofstede (2001) has suggested that organizations consider the aspect of host country culture to which performance appraisal be implemented. Hofstede (1991) has argued that there are significant differences in management styles of different countries. Therefore, it is questionable that performance appraisal principles in one country will be effective in another country without adjustments (Vance et al., 1992; Davis, 1998).

Brutus, Leslie and McDonald-Mann (2001) have suggested that it is suitable to cultures with higher values on individual achievement rather than collective achievement. As multisource feedback is focused on individual assessment, development and decision making, it may be less likely to be successful in collectivist countries like Japan, China and Thailand. In another perspective, multisource feedback may appear to be less effective as individuals will focus their attention exclusively on supervisor's feedback, while dismissing information from other raters in less hierarchical status (Brutus, Leslie, 
\& McDonald-Mann, 2001).

Harris and Moran (1996) have found that culture with different communication style has different implications on performance appraisal. Different cultures have been classified as high-context (Eastern cultures) or low-context (Western cultures) communication style (Hall 1976). For an Eastern culture like Thailand, communication is characterized to be less precise, to emphasize on listening rather than speaking and to convey information with surrounding context shared by sender and receiver. The implication in performance appraisal was that appraiser is assumed to be subjective, while feedback and criticism are indirect and subtle. Challenge on supervisor's feedback and criticism is not welcomed (Harris \& Moran, 1996).

Conversely, Western cultures are classified as low-context cultures. In terms of communication, information is transmitted in the message itself. As a result, communication is more direct and precise (Hall 1976). Employees emphasize on fairness of performance appraisal and expect that appraiser to be objective. Feedback and criticism are direct and open to be challenged by appraisee (Harris \& Moran, 1996).

As popular performance appraisal was initiated from the U.S., such as management by objectives and multisource feedback, it is important that companies adapt practices to be acceptable to host countries (Hofstede, 2001; Brutus et al., 2001). For example in collectivist society like Japan and Thailand, Hofstede (2001) has pointed that a discussion of employee performance openly is likely to clash head-on with society's harmony norm. At the same time, the subordinate may find it as a loss of face.

Davis (1998) has suggested that organizations should consider the impact of host country culture in transferring practices of performance management and appraisal. Cultural differences of nations may impact receptiveness of formal performance appraisal practices in several ways such as, use of forms and methods for providing feedback, linkage between performance and rewards, and interaction between rater and ratee (Davis 1998).

\section{Thai Cultural Dimensions and Implications on Multisource Feedback}

Seminal work by Hofstede (2001) has distinguished cultures into five dimensions from two cross-cultural researches on 72 countries. Five dimensions are power distance, individualism versus collectivism, masculinity versus femininity, uncertainty avoidance, and long-term versus short-term orientation. 
On international comparison, it was found that Thai culture was rated above average on power distance, high uncertainty avoidance and low masculinity (high femininity), above average long-term orientation and low individualism (high collectivity). The next section describes selected cultural dimensions with implications on multisource feedback.

\section{High Power Distance}

As a high power distance society, Thai organizations are hierarchical, bureaucratic and accept inequality among employees. Managers are expected to be autocratic, paternalistic and benevolent decision-maker. Managers have privileges as using one-way communication, giving order, use of power and information privilege. The multisource feedback provides an opportunity for subordinate to give feedback to supervisors. In doing so, the feedback indirectly challenge managers' existing behaviour, leadership and decisions. Managers may feel the sense of challenge and 'losing face' from unexpected results from their constituents, especially subordinates.

Negative outcomes on multisource feedback process are possible in different ways. Firstly, managers may resist the system, or choose to disregard and not cooperate with the process. Secondly, managers may challenge feedback credibility, methodology or rationale, because such practices have never happened in the culture. Thirdly, managers may revenge on those who give low ratings.

\section{High Uncertainty Avoidance}

In high uncertainty avoidance workplace, the company has hierarchical control, strong loyalty to employer, highly formalized management. Problem-solving tends to have strong appeal on technological and rational solutions with belief relies on specialists and experts. Creative ideas is often resisted, but if accepted, innovation is applied consistently (Hofstede, 2001). In such situation, the introduction of multisource feedback that provide clear feedback on individual competency and expectations may cause resistance to happen by employees' questioning on system and methodological credibility.

\section{Low Masculinity Dimension, Smooth Interpersonal Relationship}

This dimension is consistent with low masculinity dimension by Hofstede (2001) and smoother interpersonal relationship and the opposite of achievement-task cultural orientation by Komin (1990). Thai managers are characterized by emphasis on relations, 
working conditions, quality of work life, use of intuition, consensus seeking, and allowing women in management, concern on balance of work and family life (Hofstede 2001). Smooth interpersonal relationship is well-kept by preference on individuals characters as non-assertive, polite and humble personality, relaxed and pleasant interaction. Furthermore, Komin (1990) has reported that Thai values relationship more than task achievement.

The multisource feedback clarifies company competencies for individuals. The system gives priority of task over interpersonal relationships. Individual improvement is encouraged which causes some employees to receive the practice as competition at the workplace. Feedback may be interpreted as challenges on leadership behaviours and authorities.

Possible negative outcome towards the system may range from subtle ones to a more explicit one. Employees may not give honest feedback in the fear of harming interpersonal relationship and trust. In a more observable behavior, employees may try to change their behaviors to please everyone to achieve positive feedback from their constituents. As a result, a 'popular contest' may occur where employees emphasise positive scores rather than tasks.

\section{Ego (Facing-saving and Criticism-avoidance)}

In Thai workplace, Komin (1990) has suggested that managerial behaviors that provide straightforward negative performance feedback, strong criticisms, and face-toface confrontations should be avoided. In Thai culture, criticisms that are threatening to individual's ego are usually taken personally, as Thais consider criticism a social affront or an insult. In an environment, when a manager is expected to know everything under supervision, leadership of individuals may be questioned following a negative feedback. As a result, a manager with such doubt will threaten his/her status security.

As a response, managers may subject to ego-centric bias which is characterized by attribution and defensiveness (Harris \& Schaubroeck, 1988). In attribution theory, individuals attribute good performance to their own behaviour and poor performance to environmental factors. In self-defense theory, self-esteem plays a major role for cognitive balance (Farh \& Dobbins, 1989). High self-esteem individuals tended to evaluate their performance more favourably and may not accept negative evaluations as they disagree with their own self-evaluations (Baird, 1977, Farh \& Dobbins, 1989). It is expected that ego-centric bias is operating at higher degree in Thai culture. 
Consequently, negative impacts can be expected in different ways. Firstly, individuals may totally neglect feedback report, process and feedback system. This may result in poor cooperation and may extend to those in the line of authority as well. Secondly, individuals may challenge feedback and system reliability and validity. Thirdly, future retaliation of those who gives negative feedback may be possible.

\section{Grateful (Bunkhun)}

As "grateful (bunkhun)" is one of the most important values in Thai culture that effect workplace relationship. As bunkhun is psychological bond between two persons in which, one who renders the help and favours out of kindness and the other's remembering of the goodness done (Komin, 1990). In return, the receiver will reciprocate the kindness, which is not bound by time or distance. The willingness to reciprocate kindness is highly appreciated, whether in forms of tangible or intangible benefits. In terms of influence, bunkhun can greatly impact relationship quality.

In terms of possible implications on multisource feedback, negative feedback may undermine existing strength of bunkhun in organizations, especially between those of higher level and lower level. For managers, individuals may feel disappointed from discrepancy of actual results from their expectations. For subordinates, individuals may be overwhelmed by their managers' grateful bunkhun that may result in giving lenient ratings. As bunkhun is operating in all forms of relationships, it may affect peer rating by not giving honest feedback. In addition, poor implementation of feedback giving may threaten organization climate of trust and mutual help.

\section{Acceptability of Multisource Feedback by Thai Managers}

According to Leslie, Gryskiewicz and Dalton (1998), the acceptability of multisource feedback in the U.S. is based on a set of five assumptions, which are culturally bound. One of the major assumptions is that multisource feedback is based on individual concept of self-development (Leslie et al., 1998). In cross-cultural comparison, Hofstede (2001) has identified that Thai people are much less individualistic than Americans. In a lesser individualistic society like Thailand, employees will tend to value group interests, i.e. consensus in decision-making, group decision on hiring and promotion, group leadership and group training (Hofstede 2001). From this perspective, a manager may "lose-face" from receiving negative feedback from others. As a result, participants as raters and ratees may react in negative ways, for example, raters may not 
give honest feedback from fear of disturbing group harmony, and/or ratees may attribute negative feedback on external factors.

However, Vance et al. (1992) and Changrien (1995) have indicated that Thai managers have shifted to a more individualistic attitude, especially those who work in the private sector. Thai managers are more receptive to Western management principles and have valued individual achievement more than majority of Thai population (Komin 1990). Therefore, it is hypothesized that Thai managers will accept multisource feedback to be fair, accurate and practical for development.

\section{Acceptability of Appraisals by Employees, Supervisor, Peers and Subordinates}

As multisource feedback is not a unique category system, the practices vary according to the appraisal purpose and organisation readiness (Smither, et al., 1995; Bracken et al., 2001). Drawing upon the literature review, it is recommended to customize multisource feedback to be appropriate for different organizations and cultures (London et al., 1990; Leslie et al., 1998; Bracken et al., 2001).

Among major assumptions of multisource feedback, Leslie, Gryskiewics and Dalton (1998) have indicated that the process works well when managers accept and value feedback from supervisors, peers, direct reports and customers for developmental purpose. This process works well in the U.S. culture, where social equality and equal opportunities are a highly valued (Leslie et al., 1998). In this cultural dimension, Thai managers are more likely than American managers to accept and respect different power status in the workplace (Hofstede 2001). From this difference, Thai managers may not accept the feedback from subordinates who are at the lower status and/or peers who do not possess formal authority to appraise. As a result, it will be necessary to investigate Thai user reactions on appropriateness of having different rater groups to be included in multisource feedback. In particular, this research will investigate managerial reaction to feedbacks from different sources or rater groups, i.e. himself/herself, supervisor, peers and subordinates.

\section{RESEARCH METHODOLOGY}

\section{Introduction}

A research study was conducted in two large-size manufacturing and marketing company. The company manufactures and markets the leading automotive brand in Thailand with more than 2,000 employees. Due to recent economic crisis, the Japanese 
parent company has taken over and has obtained managerial control. At present, the company is majority owned by the Japanese principal company and key positions are held by Japanese expatriates, such as President, the Vice Presidents of Production and Finance. However, important positions on Commercial Division, Corporate Administration and Corporate Planning are under Thai management with the reason that these positions require local expertise.

In terms of human resource management, the department is operated under Corporate Administration, which is headed by the Thai manager. The company has recently introduced Management by Objectives (MBO) as a part of the performance management system. In order to obtain long-term business growth, the top management has explicitly stated the concern on managerial development to improve productivity, management competency and morale.

Recently, the company has introduced the Middle Management Development Course organized by external consultant/trainer. The management development course requires managers to attend training sessions of three to four days a month for duration of twelve-month period. The curriculum includes training materials on cross-cultural studies (Japanese versus Thai), managerial skills (such as communication, problem solving, creativity, presentation skills, etc.) and project management. The multisource feedback was introduced on the middle of course when managerial skills have been trained.

\section{Multisource Feedback Administration}

In this study, multisource feedback implemented has taken into consideration of cross-cultural implications as indicated in literature review. The design is customized with available knowledge on multisource feedback to avoid or minimize possible negative outcomes. The summary of design implemented is presented in Table 1. 
Table 1 Thai Cultural Values and Multisource Feedback Design Implemented

\begin{tabular}{|c|c|c|}
\hline $\begin{array}{l}\text { Unique Thai Cultural } \\
\text { Values }\end{array}$ & Possible Negative Implications & $\begin{array}{l}\text { Multisource Feedback Design } \\
\text { Implemented }\end{array}$ \\
\hline $\begin{array}{ll}\text { - } & \text { High Power Distance } \\
\text { - } & \text { Uncertainty Avoidance } \\
\text { - } & \text { Grateful (Bunkhun) }\end{array}$ & $\begin{array}{l}\text { Perceptions on practice that } \\
\text { undermine authority }\end{array}$ & $\begin{array}{l}\text { - Utilize for self-development } \\
\text { purpose only } \\
\text { - } \quad \text { Guarantee rater anonymity } \\
\text { - } \text { Increase samples to ensure rater } \\
\text { anonymity } \\
\text { - Provide training on purpose, } \\
\text { process and usage } \\
\text { - Provide external one-to-one } \\
\text { coach } \\
\text { (London et al., 1990; Greguras \& } \\
\text { Robie, 1998) }\end{array}$ \\
\hline $\begin{array}{ll}\text { - } & \text { Femininity Dimension } \\
\text { - } & \text { Smooth Interpersonal } \\
\text { - } & \text { Relationship } \\
\text { - } & \text { Grateful }\end{array}$ & $\begin{array}{l}\text { Effect on workplace } \\
\text { relationships }\end{array}$ & $\begin{array}{l}\text { Sharing success experience of } \\
\text { other companies } \\
\text { - Provide training on purpose, } \\
\text { process and usage report } \\
\text { (London et al. 1990; Alimo- } \\
\text { Metcalfe \& Beverly, 1998). }\end{array}$ \\
\hline - High Ego Orientation & Individual denial of feedback & $\begin{array}{l}\text { - Design report format to be task } \\
\text { oriented rather than self- } \\
\text { evaluation } \\
\text { - Provide external one-to-one } \\
\text { coach on 12-month program } \\
\text { (Kluger \& DeNisi, 1996; DeNisi \& } \\
\text { Kluger, 2000) }\end{array}$ \\
\hline
\end{tabular}

\section{Multisource Feedback Instrument}

Multisource feedback instrument was selected by the company and the trainer. The instrument has 50 behavioral indicators which were seen as reflecting company core values and competencies. Following the recommendations by Bracken et al. (2001), the multisource feedback administrator should consider rater motivation by using instruments with reasonable length and clarify. With the selected instrument, the form can be completed within 40 minutes. For choice of rating scale, the instrument has used 5-scale rating suggested by Landy and Farr (1980) to assist raters to deal with simultaneous categories of information and to increase psychometric properties (reliability \& validity) of the instruments. Using the guidelines by Bracken et al. (2001), the instrument has used same 5-scale rating in all items to ensure consistent rating standard for data comparison. 
Regarding the behavioral indicators in the instruments, the company believes that they are aligned with company human resource development direction as it was designed to be consistent with the training content of the 12-month program. The example of multisource feedback instrument used is provided by the following: ${ }^{1}$

Self perception:

- I believe I have strong will of concentration

- I think I am a patient person

Managerial skills:

- I train my staffs regarding the importance of communication of urgent matters that need immediate attention

- I am actively working on cross-cultural understanding and constantly try to achieve synergy in my work unit

Workplace relationship management:

- I believe my co-workers find me reliable

- I always create work atmosphere where my subordinates can approach me at any time

\section{Rater Selection}

From the suggestion by London, Wohler and Gallagher (1990), London and Beatty (1993), raters' selection guidelines were provided to this administration. As rating by supervisor is mandatory, the guideline was given to select at least 4 peers and 4 subordinates. There are two major reasons for the selection guidelines; to ensure rater anonymity and to safeguard on reports that provide average, high and low scores (London \& Beatty, 1993).

The administration has used the recommendations on peers and subordinates selections by London, Wohler and Gallagher (1990), the guidelines given to managers were to select peers/co-workers and subordinates who frequently interact with the manager, those who have different relationships (other departments or internal customers), and those who likely provide constructive response. From the suggestion by Alimo-Metcalfe and Beverly (1998), target users have the freedom to select raters and

\footnotetext{
${ }^{1}$ Due to copyright reason, this research cannot provide the full version of multisource feedback used.
} 
administration manager may assist in some cases, for example, some managers may have less than 4 subordinates, etc.

\section{Rating Administration}

From literature review, it is important that multisource feedback administration be customized to avoid negative impact from Thai work-related values, such as high power distance, high uncertainty avoidance, high ego-orientation, etc. Rating administration has to ensure users self-development purpose, provide appropriate training, and provide oneto-one coaching for advice to participants.

Following the suggestions by London et al. (1990), Alimo-Metcalfe and Beverly (1998), the company believes that rater anonymity and report confidentiality are critical success factors of multisource feedback. Therefore, human resource department has assigned a manager to administer this process to ensure confidentiality of data and create trust in this system.

Similar to performance appraisal conduct, the administrator has conducted training sessions to provide standard instructions to all raters. Using suggestions from Longenecker and Goff (1992), Waldman et al. (1998) and Bracken et al. (2001) rater training contents include overall objectives, use for self-development purpose and process of multisource feedback, different types of errors, concept of the behavioral indicators and using frame-of-reference to objectively rate the instruments.

To ensure rater anonymity, the administrator has gathered all selected raters, provided training and collected instruments in each session. Therefore, the administrator can control standard administration, training and communication on data collection. In terms of administration process, it is important to clarify procedures to all employees involved and to obtain rater motivation (Bracken et al. 2001). At the same time, instructions should be clear on administration to avoid unintentional errors from raters, such as miscoding ratees, and misusing response scale.

\section{Multisource Feedback Report Format and Usage}

For multisource feedback report format and usage guidelines, the practice has followed recommendations provided by London et al. (1990). In terms of report format, feedback report used self-rating score and average ratings of others. In terms of guidelines for managers, verbal explanation in training session was given to managers before individual report was delivered. There were two major steps in report usage. 
Firstly, managers should focus on average ratings in relations to self-ratings. Attention should be paid to large discrepancies, for example, where self-rating is much higher than others' ratings. Secondly, a closer look at discrepancies of subordinate ratings are valuable to managers in different ways; discrepancy may indicates the job requires different types of supervision, such as having subordinates vary in capabilities and work demands; discrepancy may suggests that the managers behave differently to subordinates; discrepancy may indicate geographic separation that creates differing opinions; discrepancy may suggests the manager to be aware of subordinates' needs and interests (London et al., 1990).

At the stage of results delivery, London et al. (1990), DeNisi and Kluger (2000) and Bracken et al. (2001) have suggested that a knowledgeable party such as consultant or training facilitator be used as a coach. In this aspect, the training facilitator was used to deliver the report and provide one-to-one coaching for individual managers. The facilitator has helped individuals to deal with inconsistency and formulate plan for improvement. As suggested by Kluger and DeNisi (1996), DeNisi and Kluger (2000), the system is designed to include goal-setting or action plan for improvement. According to the recommendations, this effort will significantly increase effectiveness of any feedback intervention.

\section{Research Data Collection}

There were 60 managers participated in the research (one manager has resigned from the company during the study). More than 482 questionnaires were responded on evaluation by participating managers, their supervisors, peers and subordinates. Therefore, the report for each manager consists of about 8 evaluators. The managers were divided into three classes for 12-month training program. The managers who were focus of this study were all middle managers who were responsible for functional areas of organization, e.g. finance, sales, administration, human resource, spare part, service, etc. Many managers knew each other, but may had not worked with each other before, and were peers at the time of this study.

\section{Research Questionnaire}

All 59 participants of the training program were given the evaluation of multisource feedback questionnaire by internal mail. The questionnaire consisted of 50 questions using 5-scale rating scale. The questions were divided into five sections with two major 
themes; firstly, general evaluation and self-development and secondly, perceptions on supervisory, peers, subordinate and self-ratings. All questionnaires were returned and were collected by the researcher.

\section{ANALYSIS AND RESULTS}

Using the analysis framework in relations to multisource feedback evaluation by Furnham and Stringfellow (1998), Mabey (2001), raw data of the 59 questionnaires were entered and analyzed using SPSS/PC software. For overall evaluation of multisource feedback, mean score, standard deviation and correlations of each measurement item were computed for analysis (Table 2).

From the results, it was found that users' evaluated multisource feedback fairly positive in terms of overall satisfaction (3.6 from 5-point scale) and usage for selfdevelopment purpose (3.7). This is supported by items rated higher than 3 corresponding to "agree" with the evaluation sentence that multisource feedback helps to "set personal improvement goals", "make significant effort to improve relationship", "identify improvement target" and "motivates me to best use of skills".

In terms of users' acceptability, the result is supported by having significant correlations on "overall satisfaction" and evaluative items that multisource feedback "affects me to change for the better $(r=0.45, p<0.00)$ ", the method is "fair $(r=0.51$, $\mathrm{p}<0.00$ )", and "gives accurate reflection of my behavior and performance ( $\mathrm{r}=0.56$, $\mathrm{p}<0.00)^{\prime}$.

In terms of usage for self-development purpose, overall satisfaction has significant correlations with statements that multisource feedback "motivates me to best use of my skills $(r=0.44, p<0.00)$ ", "helps me to identify target for my self-improvement $(r=0.51$, $\mathrm{p}<0.00$ )", and "I use report to set personal improvement goals ( $\mathrm{r}=0.52, \mathrm{p}<0.00)$ ".

\section{Users’ Evaluation on Multisource Feedback by Raters}

In order to evaluate users' satisfaction on multisource feedback by raters, paired ttests were performed to identify significant differences between two rating means of the whole samples on selected items (Ticehurst \& Veal, 1999). For example, mean scores were compared to identify significant differences between users' overall evaluations on fairness of ratings against ratings by supervisor, himself/herself and subordinates (Table 3).

In terms of users' acceptability of multisource feedback, the results indicated that 
users' believe that feedback from self-rating, supervisor and subordinate rating are fair and credible. In terms of accuracy, users evaluated peers ratings significantly lower than other raters. This finding suggested higher acceptance on ratings by supervisor, himself/herself and subordinates. At the same time, the results indicated that users "put significant effort to improve relationship with peers", indicating that multisource feedback users focuses development effort towards supervisory and subordinate relationship.

\section{CONCLUSION}

As organizations are facing more dynamic environment that demand more productivity with lesser resources, human resource is one of the most promising assets to be developed. With efforts to develop individuals, team, work units and organization as a whole, multisource feedback as a form of appraisal instruments can provide meaningful feedback to individuals. With multisource feedback report, individuals are provided with evaluations of self and others' perceptions. This creates an awareness of perceptions' discrepancy and may induce behavioural change in parallel with company direction.

With popularity of multisource feedback in the U.S., there are some gaps of knowledge to be filled. In the past, researches have successfully advanced to identify important issues and understand them. At this time, more researches are needed to address unresolved question-- “Is usefulness of multisource feedback universal?”. As multisource feedback is an American product, it is interesting to know if the system is applicable in Thai organizations. Together with direct usefulness on individual development, it is also important to test if multisource feedback leads to increase employee satisfaction and fairness in Thailand.

As a member of Southeast Asian countries, Thailand has very different cultural characteristics from the U.S. Using the popular cultural dimensions by Hofstede (2001), Thai culture has different characteristics from the U.S. culture, namely, power distance, individualism versus collectivism, masculinity versus femininity, uncertainty avoidance, and long-term orientation. As a result, it can be expected that Thai work-related values that effect performance appraisal practice will be very different as well. 
농

吉

孚

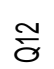

항

웅

8

$\infty$

$\tilde{\sigma}$

8

용

d

8

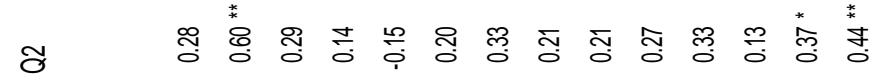

$-2$

\section{.}

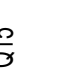

吉

9

客

定

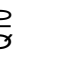

8

$\infty$

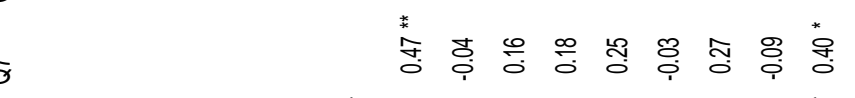

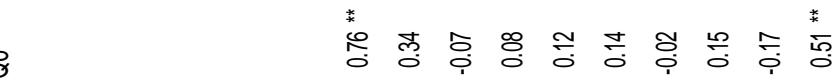

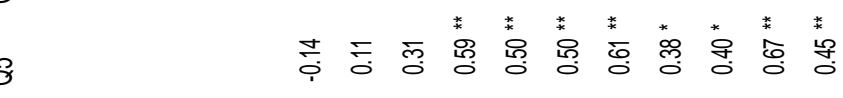

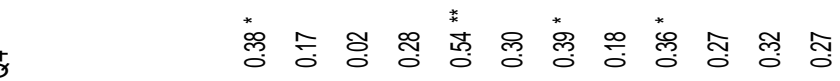

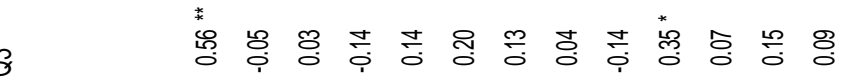

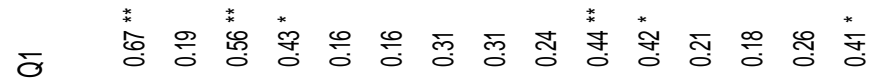

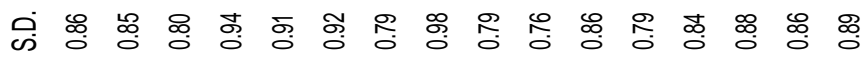

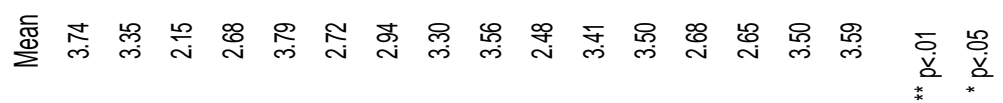

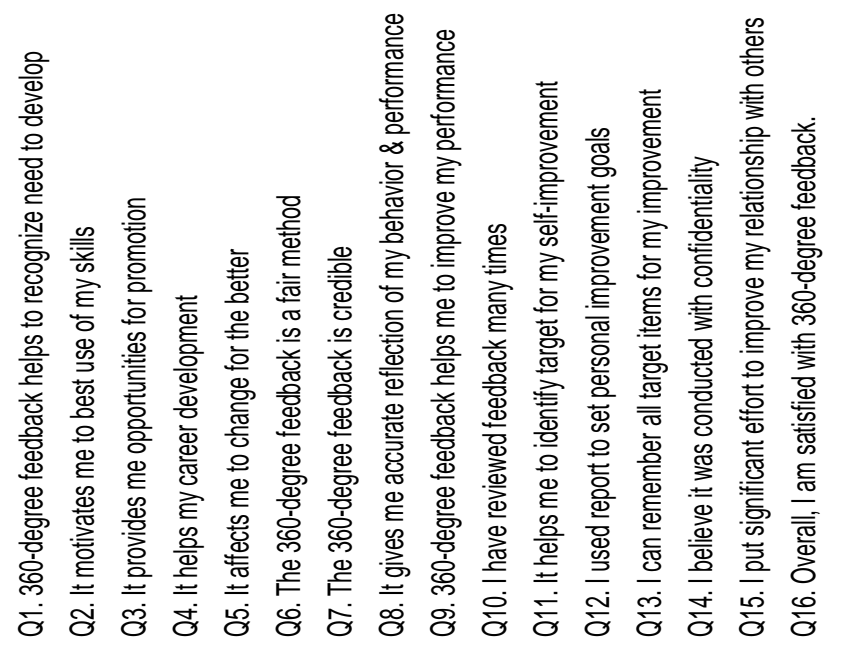




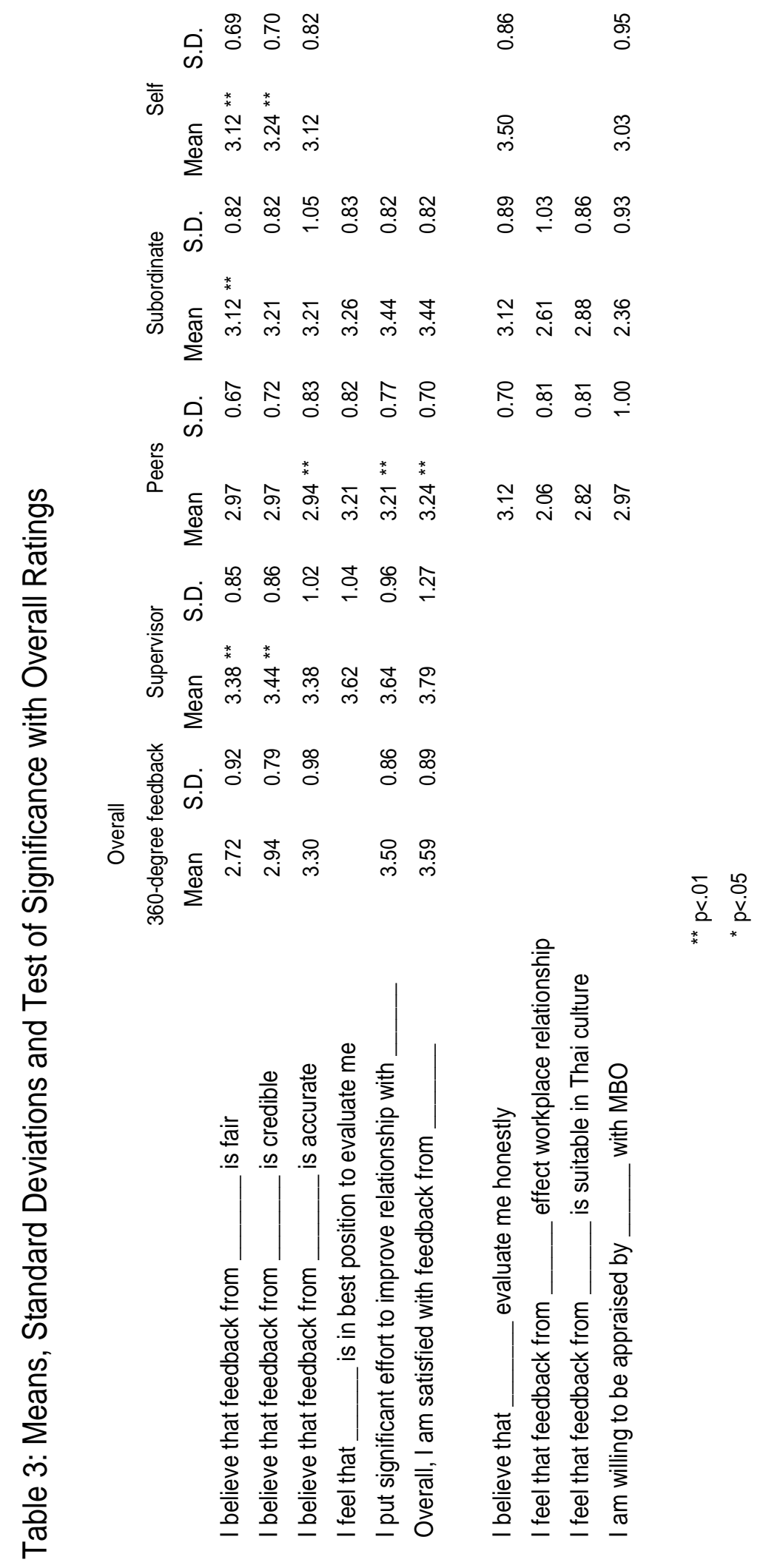


The challenge of introducing multisource feedback in Thailand can be divided into four stages. Firstly, it is important to understand Thai cultural values in the workplace. Secondly, multisource feedback system design will have to be customized to avoid potential negative implications from Thailand culture, while maintaining feedback objectives. Thirdly, human resource should assess the multisource feedback system objectively by carefully designed methods. Fourthly, companies will have to continuously evaluate and improve the multisource feedback for the next implementation.

The implementation of multisource feedback may face a certain degree of resistance in different ways. As upward feedback may be received as challenging and undermining a manager's position, it is possible to minimize negative outcome by using multi-source feedback as developmental purpose. The findings of this research have shown that the implementation of multisource feedback can be successful in Thailand as being part of training program. In addition, multisource feedback system needs guarantees on rater anonymity and feedback report confidentiality. In addition, extensive communication, rater training and employee participation will have to be performed.

In the past, Thai organizations have been exposed to American managerial theories and principles. Management principles from the U.S. have influenced Thai managerial practices, such as planning, organising and use of managerial tools. In addition, one of the most influencing sources is the American education obtained by top executives. Therefore, it is quite common to see American management practice in Thai companies. Similarly, Thai human resource management practice imported concepts on performance appraisal rating, recruitment methods, human resource information system, employee relations, compensation and benefits are common in Thai organizations. It will be another challenge to incorporate multi-source feedback as managerial development tool in Thailand.

This research suggests that multisource feedback can be used for employee development in Thailand. Multisource feedback system design should be customized in consideration of Thai work-related values. It should be use as a part of employee development where training on measured items is provided.

\section{LIMITATIONS AND KEY ASSUMPTIONS}

This research was conducted on the use of multisource feedback in two large size automotive manufacturing and marketing firms in Thailand. The multisource feedback was used for development purpose only. It was a part of 12-months management 
development program and the system and reporting were conducted with confidentiality. Following the reception of report, each participant is given one-to-one coaching and two follow-up sessions by external consultant. This research results are limited to the generalization to practices of multisource feedback with other environment, e.g. feedback for administrative purpose, feedback reception without training and coaching, and feedback coaching without experienced consultant on multisource feedback, and etc.

Regarding positive evaluation of multisource feedback for self-development, the consideration should be given to the usage within 12-month management development program. In this program, managerial competency training was provided to participants. The multisource feedback was used as a tool to set individual development, motivate participants on self-development and encourage relationship at the workplace. This research finding is limited to generalization of using multisource feedback without providing the learning environment.

\section{REFERENCES}

Alimo-Metcalfe, \& Beverly. (1998). 360 degree feedback and leadership development. International Journal of Selection and Assessment, 6(1), 35-44.

Antonioni, D. (1996). Designing an effective 360-degree appraisal feedback process. Organizational Dynamics, 25(2), 24-38.

Arvey, D. R., \& Murphy, K. R. (1998). Performance evaluation in work settings. Annual Review of Psychology, 49, 141-168.

Atwater, L., Ostroff, C., \& Yammarino, F., \& Fleenor, J. (1998). Self-other agreement: does it really matter? Personnel Psychology, 51, 577-598.

Baird, S. L. (1977). Self and supervisor ratings of performance: as related to self-esteem and satisfaction with supervision. Academy of Management Journal, 20(2), 291-300.

Bernardin, H.J., Beatty, R.W. (1984). Performance Appraisal: Assessing Human Behavior At Work. Boston: Kent.

Bernardin, J. H., Dahmus, A. S., \& Redmon, G. (1993). Attitudes of first-line supervisors toward subordinate appraisals. Human Resource Management, 32(2 \& 3), 315-324.

Bracken, D., Timmreck, C., Fleenor, J., \& Summers, L. (2001). 360 Feedback from Another Angle. Human Resource Management, 40(1), 3-20.

Brett, J., \& Atwater, L. (2001). 360 feedback: accuracy, reactions, and perceptions of usefulness. Journal of Applied psychology, 86, 930-942.

Brutus, S., \& Derayeh, M. (2002). Multisource assessment programs in organizations: An 
insider's perspective. Human Resource Development Quarterly, 13(2), 187-202.

Brutus, S., Leslie, B. J., \& McDonald-Mann, D. (2001). The Handbook of Multisource Feedback: Cross-cultural issues in multisource feedback. San Francisco: JosseyBass.

Changrien, P. (1995). Thai Society, Culture and Administration (in Thai). National Institute of Development Administration, Bangkok.

Church, H. A., \& Bracken, W. D. (1997). Advancing the state of the art of 360-degree feedback. Group and Organization Management, 22(2), 149-161.

Dierdorff, E., \& Surface, E. (2007). Placing peer ratings in context: systematic influences beyond rate performance. Personnel Psychology, 60, 93-126.

Davis, D. D. (1998). Performance Appraisal: State of the Art in Practice. San Francisco: Jossey-Bass.

DeNisi, S. A., \& Kluger, N. A. (2000). Feedback effectiveness: Can 360-degree appraisals be improved? Academy of Management Executive, 14(1), 129-139.

Edwards, M. R., \& Ewen A. (1996). 360 Feedback: the Powerful New Model for Employee Assessment \& Performance Improvement. New York: AMACOM.

Entrekin, L., \& Chung, Y. (2001). Attitudes towards different sources of executive appraisal: a comparison of Hong Kong Chinese and American Managers in Hong Kong. International Journal of Human Resource Management, 12(6), 965-987.

Farh, L. J., \& Dobbins, H. G. (1989). Effects of self-esteem on leniency bias in selfreports of performance: A structural equation model analysis. Personnel Psychology, 42, 835-853.

Frisch, M. (2001). Going around in circles with '360' tools: have they grown too popular for their own good? Human Resource Planning, 24, 7-8.

Furnham, A., \& Stringfellow, P. (1998). Congruence in job-performance ratings: a study of 360 degree feedback examining self, managers, peers and consultant ratings. Human relations, 51(4), 517-531.

Greguras, G., \& Robie, C. (1998). A new look at within-source interrater reliability of 360 degree feedback rating. Journal of Applied Psychology, 83, 960-968.

Hall, E. T. (1976). Beyond Culture. New York: Anchor Books.

Harris, M. M., \& Schaubroeck, J. (1988). A meta-analysis of self-supervisor, self-peer, and peer-supervisor ratings. Personnel Psychology, 41, 43-62.

Harris, P. R., \& Moran, R. T. (1996). Managing Cultural Differences. Houston: Gulf. Hazucha, J., Hezlett, S., \& Schneider, R. (1993). The impact of 360-degree feedback on 
management skills development. Human Resource Management, 32, 325-351.

Hofstede, G. (1991). Cultures and Organizations. London: McGraw-Hill.

Hofstede, G. (2001). Culture's Consequences: Comparing Values, Behaviors, Institutions, and Organizations. Across Nations (2nd ed.). London: Sage.

Kaplan, E. R. (1993). 360-Degree feedback PLUS: boosting the power of co-worker ratings from executives. Human Resource Management, 32(2 \& 3), 299-314.

Klausner, J. W. (1993). Reflections on Thai Culture. Bangkok: The Siam Society.

Kluger, N. A., \& DeNisi, A. (1996). The effects of feedback interventions on performance: a historial review, a meta-analysis, and a preliminary feedback intervention theory. Psychological Bulletin, 119(2), 254-284.

Komin, S. (1991). Psychology of The Thai People. Bangkok: National Institute of Development Adminstration.

Komin, S. (1990). Culture and work-related values in Thai organizations. International Journal of Psychology, 25, 681-704.

Kramar, R. (1998). Human Resource Management in Australia. Melbourne: Longman.

Landy, J. F., \& Farr, L. J. (1980). Performance rating. Psychological Bulletin, 87(1), 72107.

Laurent, A. (1986). The cross-cultural puzzle of international human resource management. Human Resource Management, 25(1), 91-101.

Leslie, J., Gryskiewicz, N., Dalton, M. (1998). Maximizing the Value of 360-Degree Feedback: A Process for Successful Individual and Organizational Development. San Francisco: Jossey-Bass.

London, M., \& Beatty, R. (1993). 360-degree feedback as a competitive advantage. Human Resource Management, 32, 353-372.

London, M., \& Smither, J. (1995). Can multi-source feedback change self-evaluations, skill development, and performance? Theory-based applications and directions for research. Personnel Psychology, 48, 803-839.

London, M., Smither, W. J., \& Adsit, J. D. (1997). Accountability: the achilles' heel of multisource feedback. Group and Organization Management, 22(2), 162-184.

London, M., Wohlers, J. A., \& Gallagher, P. (1990). A feedback approach to management development. Journal of Management Development, 9, 17-31.

Longenecker, O. C., \& Goff, J. S. (1992). Performance appraisal effectiveness: a matter of perspective. SAM Advanced Management Journal, Spring, 17-23.

Mabey, C. (2001). Closing the circle: participant views of a 360 degree feedback 
programme. Human Resource Management Journal, 11, 41-53.

Mabey, C., Salaman, G., \& Storey, J. (1998). Human Resource Management: a Strategic Introduction. Blackwell. Oxford.

Marshall, V. (2000). Human Resource Strategies: an Applied Approach. Sydney: McGraw-Hill.

Maund, L. (2001). An Introduction to Human Resource Management: Theory and Practice. New York: Palgrave.

McEvoy, G. M., \& Beatty, R. W. (1989). Assessment centers and subordinate appraisals of managers: A seven year examination of predictive validity. Personnel Psychology, 42(1), 37-52.

Moses, J., Hollenbeck, G., \& Sorcher, M. (1993). Other people’s expectations. Human Resource Management, 32, 283-297.

Nankervis, A., Compton, R., \& Baird, M. (2002). Strategic Human Resource Management. Victoria: Nelson Thomson Learning.

Nilsen, D., \& Campbell, P. D. (1993). Self-observer rating discrepancies: once an overrater, always an overrater? Human Resource Management, 32(2 \& 3), 265-281.

Peiperl, A. M. (2001). Getting 360 degrees feedback right. Harvard Business Review, 79(1), 142-147.

Pollack, D., \& Pollack, L. (1996). Using 360 degree feedback in performance appraisal. Personnel Administration, 25(4), 507-528.

Schneider, C. (1988). National versus corporate culture: implications for human resource management. Human Resource Management, 27(2), 231-246

Seifert, C. (2001). Two field experiments in the effects of combining a training workshop with multisource feedback. State University of New York at Albany: PhD thesis.

Smither, W. J., London, M., Vasilopoulos, L. N., Reilly, R. R., Millsap, E. R., \& Salvemini, N. (1995). An examination of the effects of an upward feedback program over time. Personnel Psychology, 48, 1-34.

Stone, J. (1998). Human Resource Management: Appraising and managing performance. Brisbane: Wiley.

Ticehurst, G., \& Veal A. (1999). Business Research Methods: a Managerial Approach. Longman: Australia.

Tornow, W. (1993). Editor's note: introduction to special issue on 360-degree feedback. Human Resource Management, 32, 212-219.

Vance, M. C., McClaine, R. S., Boje, M. D., \& Stage, D. H. (1992). An examination of 
the transferability of traditional performance appraisal principles across cultural boundaries. Management International Review, 32(4), 313-326.

Waldman, A. D., Atwater, E. L., \& Antonioni, D. (1998). Has 360 degree feedback gone amok? Academy of Management Executive, 12(2), 86-94.

Williams, A. (1996). Human resource management. Sydney: CCH Australia.

Wood, R., Allen, J., Pillinger, T., \& Kohn. (2000). 360 degree feedback: theory, research and practice. Sydney: McGraw-Hill. 


\section{APPENDIX}

Questionnaire for Evaluation of Multisource Assessment Usage

Alpha=0.93, $F=6.61$

\begin{tabular}{|c|c|c|}
\hline Dimension on Training and Development & Mean & S.D. \\
\hline 1. 360-degree feedback helps me to recognize the need to develop skills. & 3.74 & 0.86 \\
\hline 2. 360-degree feedback motivates me to best use of my skills. & 3.35 & 0.85 \\
\hline 3. 360-degree feedback provides me the opportunities for promotion. & 2.15 & 0.80 \\
\hline 4. 360-degree feedback helps my career development & 2.68 & 0.94 \\
\hline 5. 360-degree feedback affects me to change for the better. & 3.79 & 0.91 \\
\hline 6. 360-degree feedback is a fair method. & 2.72 & 0.92 \\
\hline 7. 360-degree feedback is credible. & 2.94 & 0.79 \\
\hline $\begin{array}{l}\text { 8. 360-degree feedback gives me accurate reflection of my working } \\
\text { behavior and performance. }\end{array}$ & 3.30 & 0.98 \\
\hline 9. 360-degree feedback helps me to improve my performance. & 3.56 & 0.79 \\
\hline 10. I have reviewed 360-degree feedback many times. & 2.48 & 0.76 \\
\hline $\begin{array}{l}\text { 11.360-degree feedback clearly help me to identify self-improvement } \\
\text { target for myself }\end{array}$ & 3.41 & 0.86 \\
\hline 12. I used 360-degree feedback report to set personal improvement goals. & 3.50 & 0.79 \\
\hline $\begin{array}{l}\text { 13. From 360-degree feedback, I can remember my self-improvement } \\
\text { target items. }\end{array}$ & 2.68 & 0.84 \\
\hline $\begin{array}{l}\text { 14. I believe that } 360 \text {-degree feedback was conducted with } \\
\text { confidentiality. }\end{array}$ & 2.65 & 0.88 \\
\hline $\begin{array}{l}\text { 15. After receiving 360-degree feedback, I made significant effort to } \\
\text { improve my relationship with others. }\end{array}$ & 3.50 & 0.86 \\
\hline 16. Overall, I am satisfied with the use of 360-degree feedback in TYM. & 3.59 & 0.89 \\
\hline Dimension on Supervisor Evaluation in 360-Degree Feedback & Mean & S.D. \\
\hline 17. I believe that supervisor's evaluation is fair. & 3.38 & 0.85 \\
\hline 18. I believe that supervisor's evaluation is credible & 3.44 & 0.86 \\
\hline $\begin{array}{l}\text { 19. I believe that supervisor's evaluation gives me accurate reflection of } \\
\text { my working behavior and performance. }\end{array}$ & 3.38 & 1.02 \\
\hline $\begin{array}{l}\text { 20. I believe that supervisor is in best position to evaluate my } \\
\text { performance. }\end{array}$ & 3.62 & 1.04 \\
\hline $\begin{array}{l}\text { 21. After receiving 360-degree feedback, I put significant effort to } \\
\text { improve my relationship with supervisor. }\end{array}$ & 3.64 & 0.96 \\
\hline 22. Overall, I am satisfied with supervisor’s evaluation. & 3.79 & 1.27 \\
\hline
\end{tabular}




\begin{tabular}{|c|c|c|}
\hline Dimension on Peers/Coworkers' Evaluation in 360-Degree Feedback & Mean & S.D. \\
\hline 23. I believe that peers/coworkers' evaluation is fair. & 2.97 & 0.67 \\
\hline 24. I believe that peers/coworkers' evaluation is credible. & 2.97 & 0.72 \\
\hline $\begin{array}{l}\text { 25. I believe that peers/coworkers' evaluation gives me accurate } \\
\text { reflection of my working behavior and performance. }\end{array}$ & 2.94 & 0.83 \\
\hline 26. I feel that peers/coworkers evaluate me honestly. & 3.12 & 0.70 \\
\hline $\begin{array}{l}\text { 27. I believe that peers/coworkers are in best position to evaluate certain } \\
\text { aspects of my performance. }\end{array}$ & 3.21 & 0.82 \\
\hline $\begin{array}{l}\text { 28. I feel that peers/coworkers evaluation has affected workplace } \\
\text { relationship. }\end{array}$ & 2.06 & 0.81 \\
\hline $\begin{array}{l}\text { 29. I feel that peers/coworkers evaluation is suitable in Thai working } \\
\text { culture. }\end{array}$ & 2.82 & 0.81 \\
\hline $\begin{array}{l}\text { 30. After receiving 360-degree feedback, I made significant effort to } \\
\text { improve my relationship with peers/coworkers. }\end{array}$ & 3.21 & 0.77 \\
\hline 31. Overall, I am satisfied with peers/coworkers evaluation. & 3.24 & 0.70 \\
\hline 32. I am willing to be appraised by peers/coworkers together with MBO. & 2.97 & 1.00 \\
\hline Dimension on Subordinate Evaluation in 360-Degree Feedback & Mean & S.D. \\
\hline 33. I believe that subordinates' feedback is fair. & 3.12 & 0.82 \\
\hline 34. I believe that subordinates' feedback is credible. & 3.21 & 0.82 \\
\hline $\begin{array}{l}\text { 35. I believe that subordinates' feedback gives me accurate reflection of } \\
\text { my working behavior and performance. }\end{array}$ & 3.21 & 1.05 \\
\hline 36. I feel that my subordinates evaluate me honestly. & 3.12 & 0.89 \\
\hline 37. I am willing to be evaluated by subordinates together with MBO. & 3.03 & 1.07 \\
\hline $\begin{array}{l}\text { 38. I believe that subordinates are in best position to evaluate certain } \\
\text { aspects of my performance. }\end{array}$ & 3.26 & 0.83 \\
\hline $\begin{array}{l}\text { 39. I felt that subordinates appraisal has affected my judgment on my } \\
\text { authority. }\end{array}$ & 2.61 & 1.03 \\
\hline 40. I feel that subordinate evaluation is suitable in Thai working culture. & 2.88 & 0.86 \\
\hline $\begin{array}{l}\text { 41. After receiving 360-degree feedback, I made significant effort to } \\
\text { improve my relationship with subordinate. }\end{array}$ & 3.44 & 0.86 \\
\hline 42. Overall, I am satisfied with subordinates’ feedback. & 3.44 & 0.82 \\
\hline 43. I am willing to be appraised by subordinate together with MBO. & 3.06 & 1.04 \\
\hline $\begin{array}{l}\text { 44. I feel that subordinates appraisal will undermine my authority if used } \\
\text { with MBO. }\end{array}$ & 2.36 & 0.93 \\
\hline
\end{tabular}




\begin{tabular}{|l|cc|}
\hline Dimension on Self Evaluation in 360-Degree Feedback & Mean & S.D. \\
\hline 45. I believe that self-evaluation is fair. & 3.12 & 0.69 \\
46. I believe that self-evaluation is credible. & 3.24 & 0.70 \\
47. I believe that self-evaluation gives me accurate reflection of my & 3.12 & 0.82 \\
$\quad$ performance. & 3.50 & 0.86 \\
48. I feel that I have evaluate myself honestly. & 3.03 & 0.95 \\
49. I like to include self-appraisal as in 360-degree feedback items with \\
$\quad \begin{array}{l}\text { MBO. } \\
\text { 50. I am willing to be appraised by 360-degree feedback method together } \\
\quad \text { with MBO form } \\
\quad \begin{array}{l}\text { (This question aims to ask your opinion on 360-degree method as a } \\
\text { part to support MBO for performance appraisal,_regardless of the } \\
\text { content used in training program) }\end{array}\end{array}$ & 2.94 & 0.76 \\
\hline
\end{tabular}

